\title{
Pioderma Gangrenoso e Lúpus Eritematoso Sistêmico
}

\section{Pyoderma Gangrenosum and Systemic Lupus Erythematosus}

\author{
Claudine J. C. Burkieviecz ${ }^{(1)}$, Leonardo Schmidt ${ }^{(1)}$, Marilia Barreto Silva $^{(2)}$, Thelma L. Skare ${ }^{(2)}$
}

\begin{abstract}
RESUMO
Pioderma gangrenoso (PG) é uma dermatose neutrofílica rara que, em algumas situações, pode ser a manifestação de uma doença sistêmica. Algumas enfermidades reumáticas estão entre as doenças que acompanham essa forma de lesão cutânea. A mais comum, neste contexto, é a artrite reumatóide. Todavia, lúpus eritematoso sistêmico e síndrome do anticorpo antifosfolípide também têm sido descritos em associação com PG. Descreve-se aqui um caso raro de associação de PG com lúpus eritematoso sistêmico e síndrome do anticorpo antifosfolípide secundária.
\end{abstract}

Palavras-chave: lúpus eritematoso sistêmico, síndrome do anticorpo antifosfolípide, pioderma gangrenoso.

\section{INTRODUÇÃO}

O pioderma gangrenoso (PG) é uma dermatose neutrofílica incomum que cursa com formação de úlceras rapidamente destrutivas e que, na maioria das vezes $(50 \%$ a $78 \%$ dos casos), associa-se a uma doença sistêmica ${ }^{(1)}$. Seu processo fisiopatológico não é bem conhecido, embora se acredite que, nestes casos, haja prejuízo da imunidade celular e anormalidades na função neutrofílica ${ }^{(1)}$.

A lesão típica de PG começa classicamente como uma pústula estéril com centro necrótico cercada por tecido de coloração vermelho-azulada, que se transforma rapidamente em uma úlcera de crescimento acelerado ${ }^{(1)}$. Seu aparecimento pode ser precipitado por um pequeno trauma,

\begin{abstract}
Pyoderma gangrenosum ( $P G$ ) is an uncommon neutrophilic dermatosis that, in some situations, may be a manifestation of a systemic disease. Among the diseases that come together with this skin lesion are some rheumatic disorders, being rheumatoid arthritis the most common. Systemic lupus erythematosus and antiphospholipid syndrome have also been described in association with PG. We describe here a rare case of association between PG and systemic lupus erythematosus with secondary antiphospholipid syndrome.
\end{abstract}

Keywords: systemic lupus erythematosus, antiphospholipid syndrome, pyoderma gangrenosum.

como punção venosa ou mesmo por cirurgias, quando não é raro que as lesões se assentem sobre a cicatriz ${ }^{(2)}$. É mais comum em membros inferiores e tronco, embora sejam descritos casos de aparecimento na cabeça, pescoço, mamas, genitais e região ocular ${ }^{(3)}$.

O diagnóstico de PG é clínico, uma vez que não existem exames laboratoriais nem histologia típica da lesão. É fundamental a exclusão de infecções, principalmente as fúngicas e tuberculose, uma vez que o seu tratamento é feito com drogas imunossupressoras ${ }^{(1)}$.

As doenças sistêmicas mais comumente associadas ao PG são retocolite ulcerativa, doenças hematológicas malignas e algumas doenças reumáticas ${ }^{(1)}$. Entre as últimas, estão

Recebido em 03/01/07. Aprovado, após revisão, em 16/05/07. Declaramos a inexistência de conflitos de interesse.

Serviço de Reumatologia do Hospital Universitário Evangélico de Curitiba.

1. Residentes do Serviço de Reumatologia do Hospital Universitário Evangélico de Curitiba, Paraná, PR

2. Professoras da Disciplina de Reumatologia do Curso de Medicina da Faculdade Evangélica de Medicina do Paraná, PR.

Endereço para correspondência: Thelma L. Skare, Rua João Alencar Guimarães, 796, CEP 80310420, Curitiba, PR, Brasil, e-mail: tskare@onda.com.br 
artrite reumatóide, espondiloartropatias soronegativas, doença de Behçet, granulomatose de Wegener e lúpus eritematoso sistêmico (LES) ${ }^{(1)}$.

O aparecimento do PG em casos de LES é considerado um evento raro ${ }^{(4)}$. Existe, na literatura, apenas a descrição de casos isolados e peculiares. Sakamoto et al.$^{(5)}$ descreveram uma paciente com PG e lúpus com lesões bolhosas e presença de anticorpos contra colágeno do tipo 7 . Waldeman e Callen descreveram outro caso em que a lesão de PG precedeu o aparecimento do LES em 8 anos $^{(6)}$. Mais recentemente, essa entidade tem-se associado com a síndrome do anticorpo antifosfolípide (SAF), seja esta primária, seja secundária $^{(4,7)}$.

Relatamos um caso raro de lúpus eritematoso sistêmico com SAF cuja manifestação inicial foi o aparecimento de lesão de PG.

\section{DESCRIÇÃO DE CASO}

Paciente feminina, 23 anos, moradora de área rural do litoral paranaense, é encaminhada do ambulatório de dermatologia com diagnóstico de pioderma gangrenoso. Relatava aparecimento de várias úlceras em membros inferiores havia 2 anos, de evolução cíclica e para as quais usava prednisona em doses variadas. Atualmente apresentava úlcera única em região inguinal direita, de 2 meses de evolução e em uso de prednisona $20 \mathrm{mg} /$ dia. Uma biópsia de pele feita no serviço de dermatologia mostrava inflamação inespecífica aguda e crônica.

A paciente relatava passado de anemia importante, tendo realizado havia $\mathrm{l}$ ano acompanhamento em um serviço de hematologia de outro hospital. Trazia em mãos um resultado de punção de medula óssea mostrando hiperplasia de série eritrocitária compatível com anemia hemolítica. Não lembrava o nome dos medicamentos utilizados naquela ocasião.

Exames atuais, realizados no serviço de dermatologia, mostravam anti-HCV, HbsAg e anti-HBS negativos, VDRL reagente em títulos de $1 / 8$, FTA ABS negativo, hematócrito de $30,2 \%$, leucócitos de $6.500 / \mathrm{mm}^{3}$, fator reumatóide de $8 \mathrm{UI} / \mathrm{ml}$ e FAN positivo no título de $1 / 2.560$, padrão homogêneo. Exame qualitativo de urina mostrava proteinúria de +++ , hemoglobina +++ . Proteinúria de 24 horas era de 2,83 g/l. Anti-dsDNA era positivo (1/256), anti-Sm, anti-Ro e anti-La, negativos. VHS $=92 \mathrm{~mm} / \mathrm{l} \stackrel{\mathrm{a}}{\mathrm{h}}$, Coombs direto, positivo.

Ainda na primeira consulta, apresentava queixas de artralgias, cansaço fácil e humor deprimido. Não existia história de fotossensibilidade, aftas, Raynaud, artrite, queixas pulmonares nem abdominais. Ao exame físico, a pressão arterial $=140 / 90, \mathrm{bcpm}=76$, afebril. $\mathrm{O}$ exame segmentar era normal, salvo úlcera em região inguinal de aproximadamente $5 \times 8 \mathrm{~cm}$, rasa e com fundo granulomatoso (Figura 1).

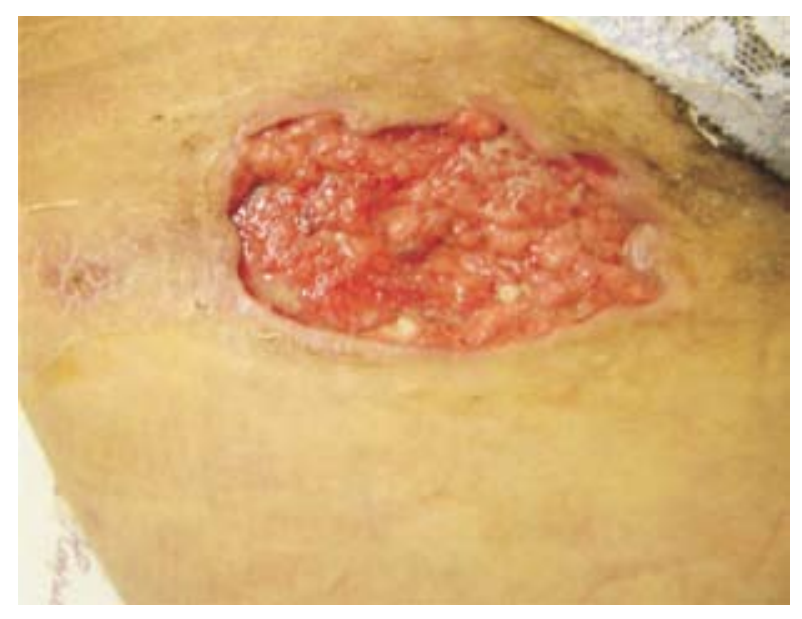

Figura 1 - Úlcera em região inguinal compatível com pioderma gangrenoso.

Foi tratada com prednisona em doses altas ( $1 \mathrm{mg} / \mathrm{kg} / \mathrm{dia})$, cloroquina, amitriptilina e tiabendazol, além de tratamento tópico para úlcera cutânea, e encaminhada para biópsia renal.

Cerca de 9 dias depois, a paciente deu entrada no pronto-socorro agitada e com queixas de dor abdominal. Segundo familiares, estava tendo dor em abdome havia 1 semana, tendo procurado posto de saúde próximo ao local de moradia e tendo sido prescrito cefalexina. A dor piorou nos últimos 3 dias com distensão abdominal importante, náuseas e vômitos. Houve interrupção de eliminação de gases e fezes nas últimas 48 horas e a paciente estava oligúrica nas últimas 24 horas. Ao exame físico, mostravase pálida, sudorípara, taquipnéica, com pressão arterial de 4 x 0 e pulso de $140 \mathrm{pm}$, filiforme. Existiam roncos pulmonares difusos e raros bolhosos em bases. $\mathrm{O}$ abdome estava distendido; era muito doloroso à palpação e sem ruídos hidroáereos. A úlcera de região inguinal direita estava parcialmente fechada e sem infecção aparente. RX de tórax foi normal e ultra-som de abdome mostrou um útero gravídico de aproximadamente 4 semanas (com feto inviável), líquido em cavidade abdominal e distensão de alças. Hemograma mostrava 16.600 leuc. $/ \mathrm{mm}^{3} \mathrm{com} 30 \%$ de bastões e granulações tóxicas. Creatinina de 1,6 mg/ dl. Admitida na UTI, recebeu fluidos endovenosos, dro- 
gas vasoativas, corticóide e antibióticos de amplo espectro (inicialmente gatifloxacina e cefepima, que foi trocada por imipenem assim que se estabeleceu o abdome como foco da infecção), sendo encaminhada para laparotomia exploradora de emergência. No transoperatório, encontrou-se trombose de vasos mesentéricos com extensa necrose de intestino grosso. Existia material purulento em cavidade abdominal. Ressecou-se cerca de $65 \mathrm{~cm}$ do intestino grosso e procedeu-se, também, à curetagem uterina. Instituiu-se medicação anticoagulante. Apesar do tratamento, a paciente evoluiu para óbito. Após a morte, obtiveram-se os seguintes resultados: anticadiolipina $\mathrm{IgG}=15 \mathrm{GPL} / \mathrm{ml}$ e $\mathrm{IgM}=80$ $\mathrm{MPL} / \mathrm{ml}$. Biópsia de rim compatível com glomerulonefrite lúpica classe 3 da OMS.

$\mathrm{O}$ estudo anatomopatológico do intestino ressecado mostrou edema, hemorragia e ulceração de mucosa, infiltrado inflamatório agudo e crônico, sem sinais de vasculite.

\section{DISCUSSÃO}

A SAF caracteriza-se pela presença de anticorpos antifosfolípides associada a tromboses venosas e/ou arteriais ${ }^{(8)}$. Essa síndrome pode aparecer isoladamente ou de maneira associada a outras doenças reumáticas, geralmente ao $\operatorname{LES}^{(8)}$.

As manifestações clínicas da SAF são variadas, estando na dependência do tipo de vaso afetado e do local em que este se encontra. Entre essas múltiplas formas de expressão, encontra-se o envolvimento de pele que, embora nem sempre valorizado pelo médico que atende esse grupo de pacientes, é bastante freqüente. Segundo Diógenes et $a l{ }^{(9)}$, em $40 \%$ dos casos de SAF (primárias e secundárias), há queixas cutâneas. São caracterizadas como livedo reticularis, acrocianose, urticárias, dermografismo, anetoderma, fenômeno de Raynaud, nódulos, úlceras cutâneas e hemorragias subungueais ${ }^{(10)}$. Livedo reticularis e úlceras de pernas são as manifestações mais facilmente reconhecidas neste contexto.

Segundo Wallace ${ }^{(11)}$, em um estudo de 520 pacientes com LES com e sem anticorpos antifosfolípides, úlceras cutâneas aparecem em torno de 5,6\%. Em outro estudo, de 200 pacientes com SAF (primárias e secundárias), verificou-se prevalência de $8 \%$ de úlceras cutâneas, sem menção a nenhum caso de pioderma gangrenoso ${ }^{(10)}$. Já Stephansson et al. ${ }^{(12)}$, ao estudarem o mesmo problema, constataram um padrão diferente nas úlceras cutâneas de pacientes com LES com e sem anticorpos antifosfolípides. Naqueles com esse auto-anticorpo, as úlceras cutâneas eram mais comuns, sendo aquelas com características de pioderma achadas exclusivamente neste último grupo. Além disso, esses mesmos autores notaram que as lesões de pioderma gangrenoso dos casos de SAF tinham algumas características diferenciais em relação aos casos de outras etiologias: os bordos eram mais nítidos e a resposta ao uso de corticóides e citostáticos era limitada ${ }^{(12)}$.

No caso descrito, a lesão de PG surgiu em paciente com LES e trombose intestinal que pode ter sido causada por SAF secundária. A ocorrência de vasculite abdominal como causa da isquemia foi afastada pelo estudo anatomopatológico do intestino ressecado. Pelos critérios de SAF (Quadro 1), além da presença dos anticorpos antifosfolípides é necessária presença de trombose documentada ou morbidade gestacional. Os anticorpos do grupo anticardiolipina $\mathrm{IgG}$, e não anticardiolipina $\operatorname{IgM}$, como o apresentado pela paciente, são os mais associados à trombose ${ }^{(13)}$. É necessário notar que estado de hipercoagulação pode ter sido causado ou agravado pela gravidez e síndrome nefrótica concomitantes.

QuAdro 1

CRITÉRIOS DIAGNÓSTICOS PARA A SÍNDROME DO ANTICORPO ANTIFOSFOLÍPIDE ${ }^{(14)}$

\section{Clínicos}

Trombose (um ou + episódios) arterial, venosa ou de pequenos vasos.

Confirmada por estudos de imagem ou biópsia

Morbidade na gravidez: um ou + mortes fetais inexplicadas com feto com pelo menos 10 semanas e sem alterações morfológicas; ou um ou mais partos prematuros de RN morfologicamente normal, antes da $34^{\text {a }}$ semana de gestação com pré-eclâmpsia, eclâmpsia ou insuficiência placentária; ou três ou mais abortos espontâneos e não explicados de outra maneira

\section{Laboratoriais}

Anticorpos anticardiolipina IgG ou IgM em títulos médios ou altos em duas ocasiões (com intervalo de 12 semanas)

Presença de lúpus anticoagulante (LAC) em duas ou mais ocasiões (com intervalo de 12 semanas)

Anticorpos anti- $\beta 2$ microglobulina em títulos altos em duas ou mais vezes (com intervalo de 12 semanas)

Diagnóstico definitivo: um critério clínico + um laboratorial

Todavia, o caso ilustra de maneira clara a possibilidade de associação de PG com presença de SAF, cujo conhecimento pode levar o médico a diagnosticar, com maior prontidão, eventuais eventos trombóticos que venham a aparecer nesses pacientes. Infelizmente, a evolução catastrófica impediu a observação do papel de anticoagulação sobre a lesão cutânea. 


\section{REFERÊNCIAS}

1. Trost LB, Mc Donnell JK: Important cutaneous manifestations of inflammatory bowel disease. Post Grad Med J 81: 580-5, 2005.

2. White G, Cox NH: Doenças inflamatórias e infiltrados cutâneos. In: White G, Cox NH (eds). Doenças de pele. São Paulo: Manole, 2003. pp. 109-31.

3. Wines $\mathrm{N}$, Wines $\mathrm{M}$, Ryman $\mathrm{W}$ : Understanding pyoderma gangrenosum: a review. Med Gen Med 3(3): 6, 2001. < http:// www.medscape.com>

4. Schimid M-H, Hary C, Marstaller B, Wendtner C-M: Pyoderma gangrenosum associated with the secondary antiphospholipid syndrome. Eur J Dermatol 8: 45-7, 1998.

5. Sakamoto T, Hashimoto T, Furukawa F: Pyoderma gangrenosum in a patient with bullous systemic lupus erythematosus. Eur J Dermatol 12: 485-7, 2002.

6. Waldeman MA, Callen JP: Pyoderma gangrenosum preceding the diagnosis of systemic lupus erythematosus. Dermatol 210: 64-7, 2005.

7. Schlesinger IH, Farber JA: Cutaneous ulceration resembling pyoderma gangrenosum in the primary antiphospholipid syndrome: a report of two cases and review of the literature. J La State Med Soc 147: 357-61, 1995.
8. Gezer S: Antiphospholipid syndrome. Dis Mon 49: 691-742, 2003.

9. Diógenes MJN, Diógenes PCN, Carneiro RMM, Ribeiro Neto CC, Duarte FB, Holanda RRA: Cutaneous manifestations associated with antiphospholipid antibodies. Int J Dermatol 43: 632-7, 2004.

10. Frances C, Niang S, Lafitte E, Pelletier F, Costedoat N, Piette JC: Dermatologic manifestations of antiphospholipid syndrome: two hundred consecutive cases. Arthritis Rheum 52: 1785-93, 2005.

11. Wallace DJ: Clinical and laboratory features of systemic lupus erythematosus. In: Wallace DJ, Hahn BH, eds. Dubois' lupus erythematosus. Baltimore: Williams \& Wilkins, 2002. pp. 693-722.

12. Stephansson EA, Niemi K, Jouhikainen T, Vaarala O, Palosuo T: Lupus anticoagulant and the skin. Acta Derm Venereol 71: 416-22, 1991.

13. Sammaritano LR, $\mathrm{Ng} \mathrm{S}$, Sobel R, et al.: Anticardiolipin IgG subclasses. Association of IgG2 with arterial and/or venous thrombosis. Arthritis Rheum 40: 1998-2006, 1997.

14. Bermas BL, Erkan D, Schur PH: Clinical manifestations and diagnosis of antiphospholipid syndrome. In: Rose B (ed.). Uptodate.com, versão 15.1. <http: http:www.uptodate.com>, abril de 2007. 